\title{
Antiproliferative and apoptotic effects of telmisartan in human colon cancer cells
}

\author{
LUCAS D. LEE*, BENJAMIN MAFURA, JOHANNES C. LAUSCHER, \\ HENDRIK SEELIGER, MARTIN E. KREIS and JÖRN GRÖNE* \\ Department of General, Visceral and Vascular Surgery, Campus Benjamin Franklin, \\ Charité-University of Medicine Berlin, Berlin D-12203, Germany
}

Received December 15, 2013; Accepted June 5, 2014

DOI: $10.3892 / \mathrm{ol} .2014 .2592$

\begin{abstract}
Telmisartan is an angiotensin $\mathrm{I}_{\left(\mathrm{AT}_{1}\right)}$ receptor blocker used in the treatment of essential hypertension, with partial peroxisome proliferator-activated receptor $\gamma$ (PPAR $\gamma$ ) agonism. In prior studies, PPAR $\gamma$ activation led to apoptosis and cell cycle inhibition in various cancer cells. The aim of the present study was to investigate the potential antiproliferative and apoptotic effects of telmisartan by partially activating PPAR $\gamma$. HT-29, SW-480 and SW-620 cells were incubated with telmisartan $(0.2-5 \mu \mathrm{M})$ or the full agonist, pioglitazone $(0.2-5.0 \mu \mathrm{M})$. The antiproliferative and apoptotic effects of telmisartan in the human colon cancer cells were significant at therapeutic serum concentrations, and telmisartan exhibited a potency at least equivalent to the full PPAR $\gamma$ agonist, pioglitazone. The antiproliferative and apoptotic effects of pioglitazone in the human colon cancer cells were not completely deregulated by PPAR $\gamma$ blockade with GW9662. In the telmisartan-treated cells, PPAR $\gamma$ blockade resulted in an increased antiproliferative and apoptotic effect. These effects are not entirely explained by PPAR $\gamma$ activation, however, possible hypotheses that require further experimental investigation are as follows: i) Ligand-independent PPAR $\gamma$ activation through the activation-function 1 domain; ii) a PPAR $\gamma$-independent mechanism; or iii) independent antiproliferative and apoptotic effects through GW9662.
\end{abstract}

Correspondence to: Mr. Lucas D. Lee, Department of General, Visceral and Vascular Surgery, Campus Benjamin Franklin, Charité-University of Medicine Berlin, 30 Hindenburgdamm, Berlin D-12203, Germany

E-mail: lucas.lee@charite.de

"Contributed equally

Key words: apoptosis, peroxisome proliferator-activated receptor $\gamma$, angiotensin I receptor blocker, colon cancer, antiproliferative, telmisartan

\section{Introduction}

Telmisartan is an antihypertensive drug that exerts its effect by antagonizing the angiotensin $\mathrm{I}\left(\mathrm{AT}_{1}\right)$ receptor blocker (ARB). Beyond this mechanism, Shupp et al (1) revealed partial peroxisome proliferator-activated receptor (PPAR) agonism in 3T3-L1 preadipocytes. PPAR belongs to the steroid hormone receptor superfamily (2) and can be divided into three types: PPAR $\alpha, \operatorname{PPAR} \beta / \delta$ and PPAR $\gamma$. Alternative splicing of PPAR $\gamma$ leads to four isoforms: PPAR $\gamma_{1-4}$. Translating the mRNA of PPAR $\gamma_{1,3,4}$ results in an identical protein (3). By contrast, the PPAR $\gamma_{2}$ protein differs from PPAR $\gamma_{1}$ due to the additional 30 amino acids at its $\mathrm{N}$-terminal, and it predominantly exists in adipocytes, but is also highly expressed in colon epithelium, pancreatic $\beta$ cells, endothelial tissue and macrophages. In addition, PPAR $\gamma_{1}$ is present in human urological cancer cells (i.e., renal cell, prostate, bladder and testicular cancer) (4) and colon cancer cells (5), where ligand-dependent activation by antidiabetic drugs, such as thiazolidinediones, which include pioglitazone, rosiglitazone, troglitazone and ciglitazone, leads to apoptosis (6) and an antiproliferative effect (7).

Arterial hypertension and colorectal cancer (CRC) have a high prevalence in industrialized nations, with an estimated proportion of $25 \%$ for hypertension and an age standardized incidence (Europe) for CRC of $67.0 \%$ for males and $44.5 \%$ for females in Germany (8). Synchronous manifestation is common, however, at present, it is unclear whether telmisartan partially activates PPAR $\gamma_{1}$ in human colon cancer cells and whether its partial agonism is sufficient for inhibiting proliferation and stimulating apoptosis in a significant manner.

\section{Materials and methods}

Cell culture. Human colon cancer cells (HT-29, SW-480 and SW-620) were obtained from the American Type Culture Collection (Rockville, MD, USA). The HT-29 and SW-480 cells originated from well-differentiated colorectal adenocarcinoma (9) and the SW-620 cells were derived from colorectal lymph node metastasis. The cell lines were maintained in RPMI-1640 culture medium (Life Technologies, Darmstadt, Germany), containing $10 \%$ fetal calf serum and $1 \%$ penicillin 
and streptomycin (all Biochrom AG Biotechnologie, Berlin, Germany), at $37^{\circ} \mathrm{C}$ in a $5 \% \mathrm{CO}_{2}$ humidified atmosphere. Each cell line was treated with telmisartan (0.2-5.0 $\mu \mathrm{M}$; Boehringer Ingelheim, Ingelheim, Germany) or the full PPAR $\gamma$ agonist, pioglitazone (0.2-5.0 $\mu \mathrm{M}$; Zhejiang Huahai Pharmaceutical Co., Ltd., Zhejiang, China), as a positive control for $24 \mathrm{~h}$. Pioglitazone and telmisartan were each dissolved in $0.05 \%$ dimethyl sulfoxide (DMSO; Carl Roth GmbH \& Co., KG, Karlsruhe, Germany). DMSO served as a negative control.

MTT cytotoxicity assay. The measured activity of mitochondrial succinate dehydrogenase quantitatively determines the degree of cytotoxicity. The enzyme converts tetrazolium salt (MTT; Sigma-Aldrich Chemie GmbH, Taufkirchen, Germany) into a blue dye, and the absorption is measured. Higher levels of absorption indicate higher levels of enzyme activity and increased cell viability. According to the manufacturer's instructions, the cells were detached using $3 \mathrm{ml}$ trypsin and then transferred to a 96-well microplate. Each well contained $3 \times 10^{3}$ cells per $0.2 \mathrm{ml}$, and the cells were incubated at $37^{\circ} \mathrm{C}$ and $95 \%$ relative atmospheric humidity for $24 \mathrm{~h}$. Following three days of incubation with $100 \mu \mathrm{l}$ medium and $10 \mu \mathrm{l}$ MTT solution [50 mg/10 ml phosphate-buffered saline (PBS); PAA Laboratories $\mathrm{GmbH}$, Cölbe, Germany ], the cells were incubated for a further four hours. Cell lysis was initiated by the addition of $100 \mu \mathrm{l}$ SDS (10\%; $5 \mathrm{~g} / 50 \mathrm{ml}$ double-distilled water) purchased from Carl Roth GmbH \& Co., KG. The cell suspension was incubated overnight and the absorbance at $570 \mathrm{~nm}$ was measured on the following day with a reference at $650 \mathrm{~nm}$.

Cell count. Following $24 \mathrm{~h}$ of incubation with DMSO, pioglitazone and telmisartan in the presence or absence of the PPAR $\gamma$ antagonist, GW9662, the cell culture medium was carefully removed, followed by multiple PBS-washing cycles. Cell counting was performed using a Neubauer cell count chamber (Brand GmbH + Co., KG, Wertheim, Germany).

Caspase 3-7 assay. The Caspase-Glo ${ }^{\circledR}$ 3/7 assay (AnaSpec Inc., Seraing, Belgium) is a homogeneous, luminescent assay that measures caspase- 3 and -7 activity. The assay provides a luminogenic caspase-3/7 substrate, which contains the Asp-Glu-Val-Asp tetrapeptide sequence, in a reagent optimized for caspase activity, luciferase activity and cell lysis. Adding a single Caspase-Glo ${ }^{\circledR}$ 3/7 reagent in an add-mix-measure format results in cell lysis, followed by caspase cleavage of the substrate and generation of a 'glow-type' luminescent signal, produced by luciferase. Luminescence is proportional to the amount of caspase activity present.

Quantitative polymerase chain reacton ( $q P C R$ ). Primers were purchased from TIB Molbiol Syntheselabor GmbH (Berlin, Germany) with the following sequences: PPAR $\gamma$ Sense, 5'-CAAGCCCTTCACTACTGTTG-3' and antisense, 5'-CTTTATCTCCACAGACACG-3'; and $\mathrm{AT}_{1}$ receptor sense, 5'-ACAGCTTGGTGGTGATAGTC-3' and antisense, 5'-CAATGCTGAGACACGTGAG-3'. The qPCR was performed using the Roche LightCycler ${ }^{\circledR}$ carousel-based system (Roche Diagnostics GmbH, Mannheim, Germany) under the following conditions: Activation at $95^{\circ} \mathrm{C}$ for $10 \mathrm{~min}$; 40 cycles of amplification at $95^{\circ} \mathrm{C}$ for $5 \mathrm{sec}, 64^{\circ} \mathrm{C}$ for $10 \mathrm{sec}$ and $72^{\circ} \mathrm{C}$ for $20 \mathrm{sec}$; and a brief melting curve analysis at $95^{\circ} \mathrm{C}$ and $65^{\circ} \mathrm{C}$ for $15 \mathrm{sec}$, followed by an increase of $0.1^{\circ} \mathrm{C} / \mathrm{sec}$ to $95^{\circ} \mathrm{C}$.

Statistical analyses. Statistical significance was determined using the independent Student t-test, SPSS Version 19.0.1 (IBM, Armonk, NY, USA). P $<0.05$ was considered to indicate a statistically significant difference.

\section{Results}

Telmisartan affects cell viability of human colon cancer cells. The incubation of the human colon cancer cell lines with pioglitazone and telmisartan exhibited a dose-dependent effect on cell viability (Fig. 1), while incubation of the HT-29 cells with $0.2 \mu \mathrm{M}$ telmisartan resulted in $98.65 \%$ cell viability $(\mathrm{P}>0.05)$. Additional blocking of PPAR $\gamma$ with $2.5 \mu \mathrm{M}$ GW9662 resulted in 96.60\% ( $\mathrm{P}>0.05)$ cell viability (telmisartan vs. telmisartan combined with GW9662; $>>0.05$ ). In the SW-480 and SW-620 cells, incubation with $0.2 \mu \mathrm{M}$ telmisartan alone resulted in a cell viability of 98.13 and $96.33 \%$ (P>0.05), respectively. In the presence of $2.5 \mu \mathrm{M}$ GW9662, the cell viability was reduced to 88.53 and $86.77 \%(\mathrm{P}<0.001)$. A concentration of $0.2 \mu \mathrm{M}$ pioglitazone alone resulted in 97.31, 99.63 and $96.74 \%$ cell viability for the HT-29, SW-480 and SW-620 cells, respectively ( $P>0.05)$. Additional blocking of PPAR with $2.5 \mu \mathrm{M}$ GW9662 resulted in 98.10 ( $\mathrm{P}>0.05)$, 95.23 and $91.70 \%(\mathrm{P}<0.001)$ cell viability for the HT-29, SW-480 and SW-620 cells, respectively. No significant differences were identified with regard to the effect on cell viability between telmisartan and pioglitazone regardless of the use of GW9662 in all three human colon cell lines.

Antiproliferative effect of telmisartan in human colon cancer cells. Telmisartan and pioglitazone inhibited cell proliferation in a dose-dependent manner (Fig. 2). Telmisartan (0.2 $\mu \mathrm{M})$ significantly reduced cell survival in the HT-29, SW-480 and SW-620 cells $(73.33,80.56$ and $57.75 \%$, respectively; $\mathrm{P}<0.001)$. Additional PPAR $\gamma$ blockage with $2.5 \mu \mathrm{M}$ GW9662 led to a significant increase in cell survival in the HT-29 and SW-620 cells ( 80.78 and $74.59 \%$, respectively; $\mathrm{P}<0.001$ ), however, this increase was not observed in the SW-480 cells (80.08\%; P>0.05). The incubation of the HT-29, SW-480 and SW-620 cells with $0.2 \mu \mathrm{M}$ pioglitazone resulted in a significantly reduced cell count $(88.51,83.49$ and $79.30 \%$; $\mathrm{P}<0.001)$. However, no significant differences in cell count were observed by adding $2.5 \mu \mathrm{M}$ GW9662 (90.27\% for HT-29, $80.56 \%$ for SW-480 and 78.21\% for SW-620; P>0.05). The difference in the antiproliferative effect between pioglitazone and telmisartan was not significant in the HT-29 cells, regardless of the use of GW9662. By contrast, the difference in the antiproliferative effect was significant in the SW-480 cells $(\mathrm{P}<0.001$; $\mathrm{P}<0.05$ with GW9662), as well as in the SW-620 cells in the absence of GW9662 ( $\mathrm{P}<0.05 ; \mathrm{P}>0.05$ with GW9662).

Telmisartan induces apoptosis. The induction of apoptosis was determined by the caspase 3/7 assay (Fig. 3). Significant caspase $3 / 7$ activation was measured with $0.2 \mu \mathrm{M}$ pioglitazone and telmisartan $(\mathrm{P}<0.05)$ in all three colon cancer cell lines (HT-29, SW-480 and SW-620). However, no significant difference was observed between the apoptotic effects of telmisartan 
A
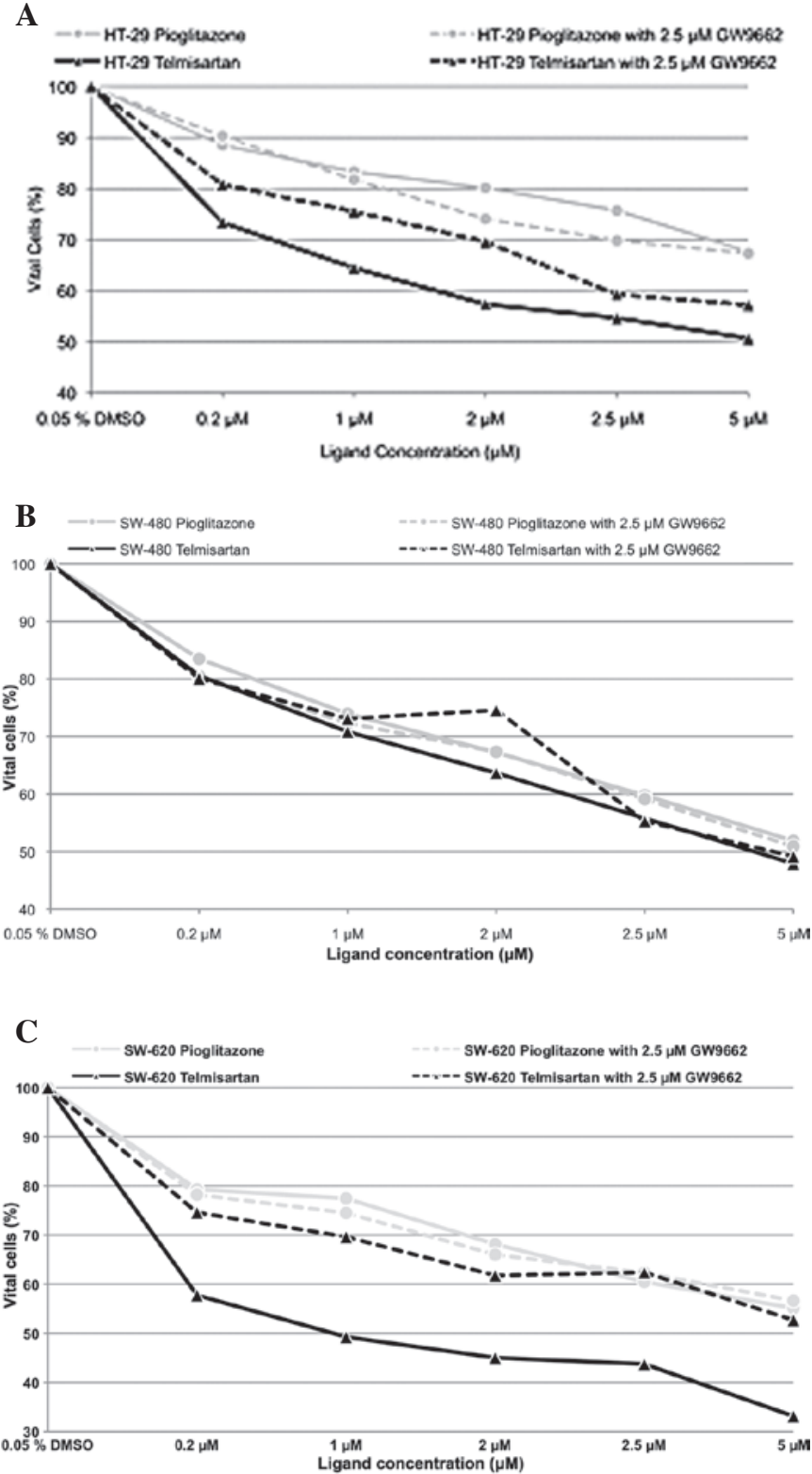

Figure 1. Determination of antiproliferative effect by cell count in a Neubauer cell chamber. (A) HT-29, (B) SW-480 and (C) SW-620 cells were incubated with pioglitazone $(0-5 \mu \mathrm{M})$ and telmisartan $(0-5 \mu \mathrm{M})$ for $24 \mathrm{~h}$. The percentage of vital cells revealed that the antiproliferative effect of the partial PPAR $\gamma$-agonist, telmisartan, was greater than that of the full PPAR $\gamma$ agonist, pioglitazone. PPAR $\gamma$, peroxizome proliferator-activated receptor $\gamma$; DMSO, dimethyl sulfoxide.

and pioglitazone. Similarly, the addition of $2.5 \mu \mathrm{M}$ of the PPAR $\gamma$ blocker, GW9662, also resulted in significant caspase 3/7 activation $(\mathrm{P}<0.05)$ in all three colon cancer cell lines. No significant differences were identified in caspase $3 / 7$ activation between telmisartan alone versus telmisartan in combination with GW9662, and the same was true for pioglitazone.

Telmisartan downregulates PPAR $\gamma$ and upregulates cystatin A (CSTA). PPAR $\gamma$ was found to downregulate its relative mRNA expression following ligand activation (Fig. 4). Relative PPAR $\gamma$ mRNA expression was significantly downregulated in the HT-29, SW-480 and SW-620 cells with $0.2 \mu \mathrm{M}$ telmisartan $(\Delta 0.53, \Delta 0.53$ and $\Delta 0.36$; $\mathrm{P}<0.05)$. The addition of $2.5 \mu \mathrm{M}$ GW9662 also resulted in a
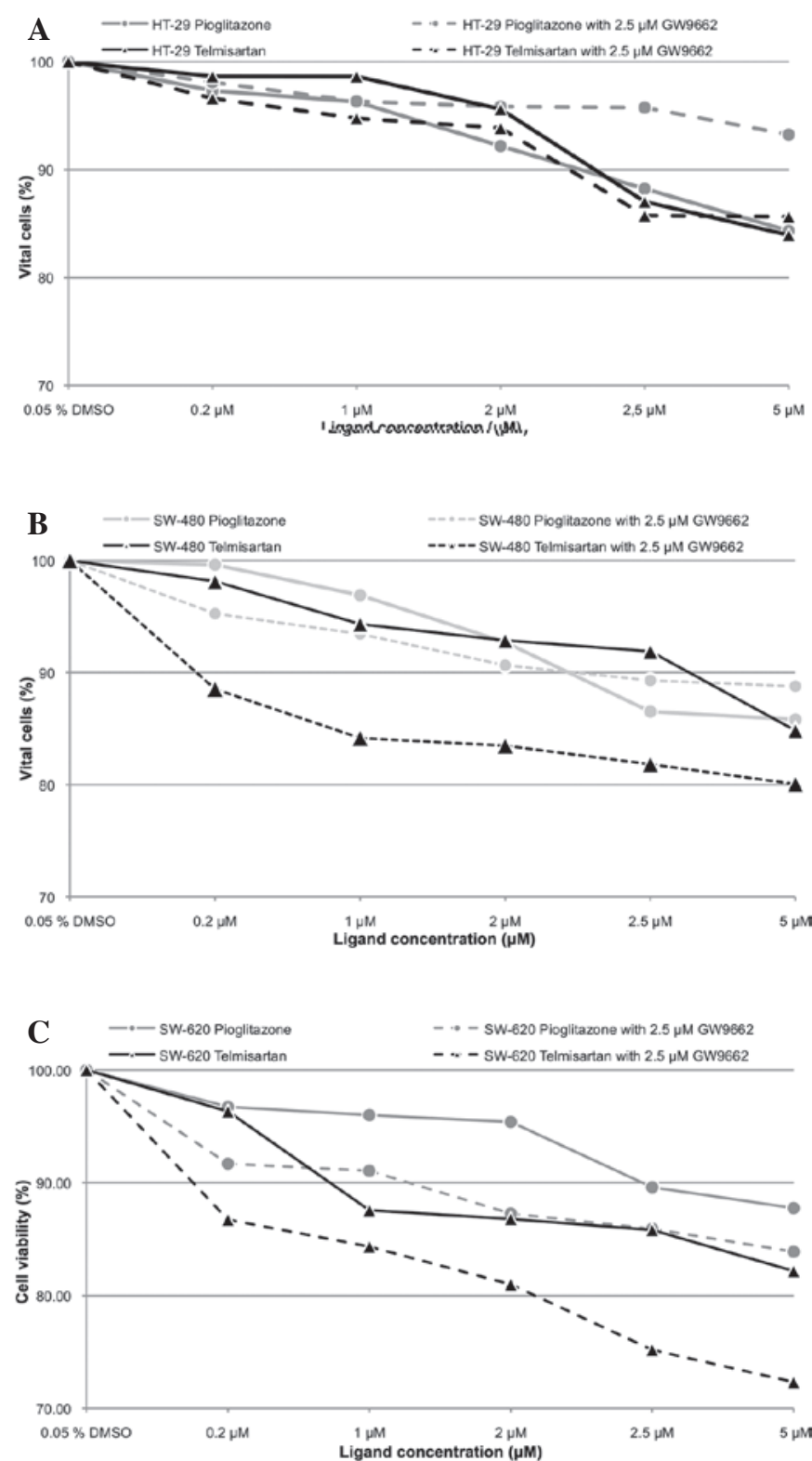

Figure 2. Determination of cell viability by MTT assay. (A) HT29, (B) SW-480 and (C) SW620 cells were incubated with pioglitazone $(0.2-5 \mu \mathrm{M})$ and telmisartan $(0.2-5 \mu \mathrm{M})$ for $24 \mathrm{~h}$. The percentages of vital cells are shown with respect to ligand concentration. DMSO, dimethyl sulfoxide; Pio, pioglitazone.

significant downregulation of relative PPAR $\gamma$ mRNA expression (HT-29, $\Delta 0.34$; SW-480, $\Delta 0.67$; and SW-620, $\Delta 0.31$; $\mathrm{P}<0.05)$. However, no significant differences were observed between telmisartan alone and telmisartan combined with GW9662. The incubation of the HT-29, SW-480 and SW-620 cells with $0.2 \mu \mathrm{M}$ pioglitazone also resulted in a significant downregulation of relative PPAR $\gamma$ mRNA expression $(\Delta 0.27$, $\Delta 0.32$ and $\Delta 0.27$, respectively; $\mathrm{P}<0.05)$. PPAR $\gamma$ blockage did not neutralize the effect of pioglitazone on PPAR $\gamma$ mRNA expression in all three colon cancer cell lines (HT-29, $\Delta 0.42$; SW-480, 40.48; and SW-620, 0.27; P<0.05). $\mathrm{AT}_{1}$ receptor mRNA was downregulated significantly through telmisartan in all three colon cancer cell lines $(\mathrm{P}<0.05)$, as predicted. Notably, pioglitazone had the same effect in all three colon cancer cell lines $(\mathrm{P}<0.05)$. CSTA, a well-known PPAR $\gamma_{1}$ 

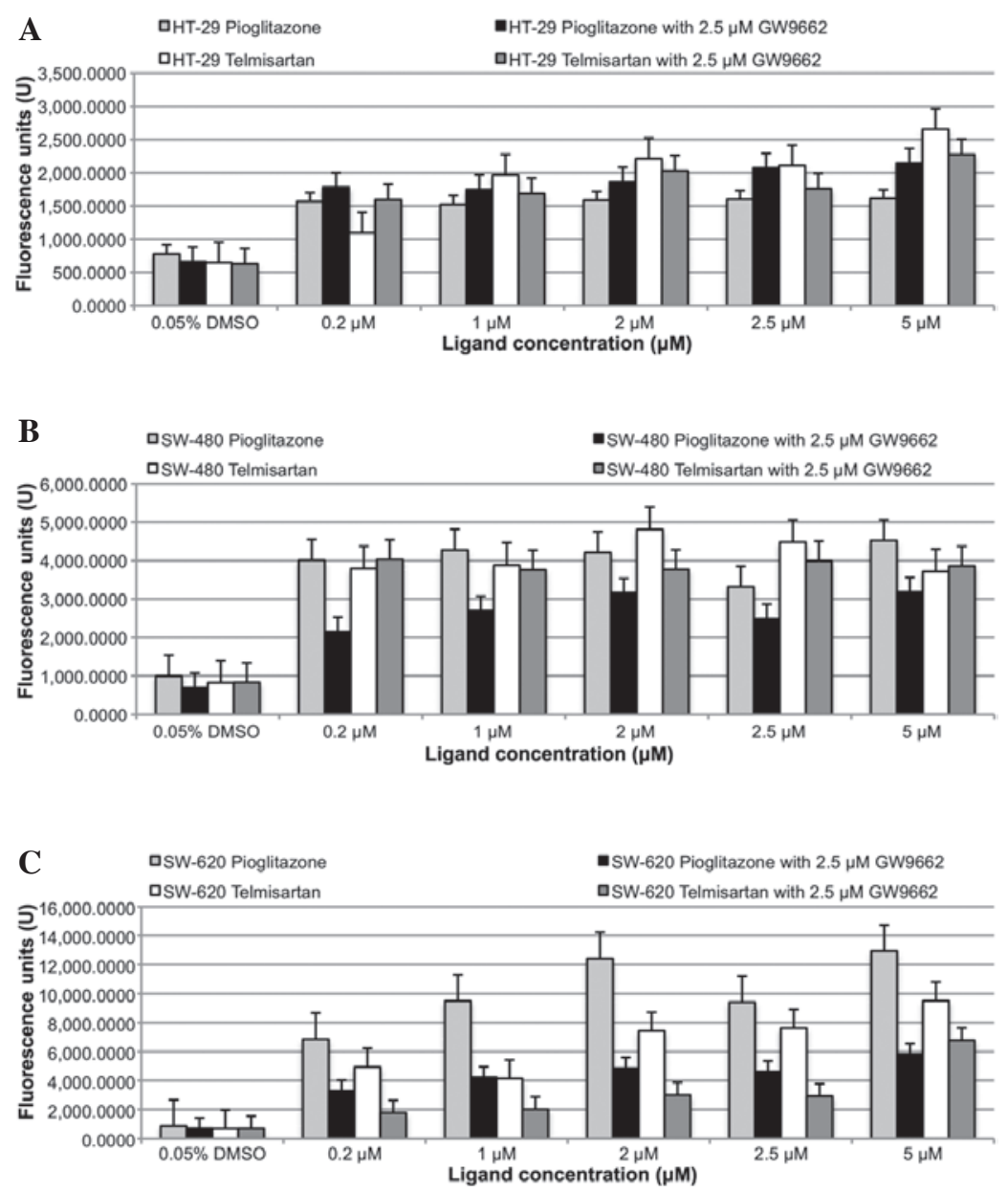

Figure 3. Caspase 3/7 assay of (A) HT-29, (B) SW-480 and (C) SW-620 cells following $24 \mathrm{~h}$ of incubation with pioglitazone and telmisartan, in the absence or presence of $2.5 \mu \mathrm{M}$ of the peroxizome proliferator-activated receptor $\gamma$ antagonist, GW9662. DMSO, dimethyl sulfoxide.

target gene, which is upregulated upon PPAR $\gamma$ activation, was used as a positive control. Relative CSTA mRNA expression was not significantly affected by $0.2 \mu \mathrm{M}$ telmisartan or telmisartan combined with $2.5 \mu \mathrm{M}$ GW9662 in the HT-29 and SW-620 cells. While significant upregulation was observed in the SW-480 cells $(\Delta 0.5 ; \mathrm{P}<0.05)$, the addition of $2.5 \mu \mathrm{M}$ GW9662 (P>0.05) did not cause this result. Relative CSTA mRNA expression in the HT-29 cells was not significantly affected by $0.2 \mu \mathrm{M}$ pioglitazone, alone or in combination with GW9662. By contrast, relative CSTA mRNA expression in the SW-620 cells was significantly upregulated $(\Delta 0.50$ alone and $\Delta 0.20$ with GW9662; $\mathrm{P}<0.05)$.

\section{Discussion}

The thiazolidinedione, pioglitazone, is an oral antidiabetic drug that enhances insulin sensitivity through PPAR $\gamma$ activation. However, it also activates PPAR $\gamma$ in colon cancer cells in vitro, inducing the suppression, differentiation, apoptosis and reversal of malignant changes $(7,10)$. Telmisartan is an ARB and a common antihypertensive drug with partial PPAR $\gamma$-agonism (1). Therefore, it is of note whether telmisartan partially activates PPAR $\gamma_{1}$ in colon cancer cells, subsequently inducing a reduction in cell viability, inhibiting cell proliferation and inducing apoptosis.
Following the oral intake of $20-120 \mathrm{mg}$ telmisartan by hypertensive patients, the therapeutic serum concentration has been measured to range between 0.035 and $1.036 \mathrm{mM}$ (11). Therefore, in the present study, various colon cancer cells were incubated with telmisartan and pioglitazone in comparable concentrations ranging between 0.2 and $5.0 \mu \mathrm{M}$. This resulted in a dose-dependent reduction in cell viability, the inhibition of cell proliferation and the induction of apoptosis in all three colon cancer cell lines. As predicted, the effect of the full agonist, pioglitazone, was diminished by adding the synthetic PPAR $\gamma$ antagonist, GW9662. PPAR $\gamma$ blockage with GW9662 in the presence of telmisartan as a partial PPAR $\gamma$ agonist did not lead to the diminished inhibition of the cell proliferation and cell viability of pioglitazone. However, the reduction in cell viability and the antiproliferative effect in the SW-480 and SW-620 cells were further increased compared with use of telmisartan alone. Furthermore, telmisartan exhibited an apoptotic effect equivalent to the full PPAR $\gamma$ agonist, pioglitazone. Contrary to the prediction of a decreased apoptotic effect following the addition of the PPAR $\gamma$ GW9662, a significant induction of caspase 3/7 was observed, indicating PPAR $\gamma$-independent apoptosis induction. Following ligand-dependent activation, the PPAR $\gamma$ mRNA level was characteristically downregulated as a negative feedback mechanism, whilst upregulating the mRNA of its target genes, including CSTA. Incubation with 

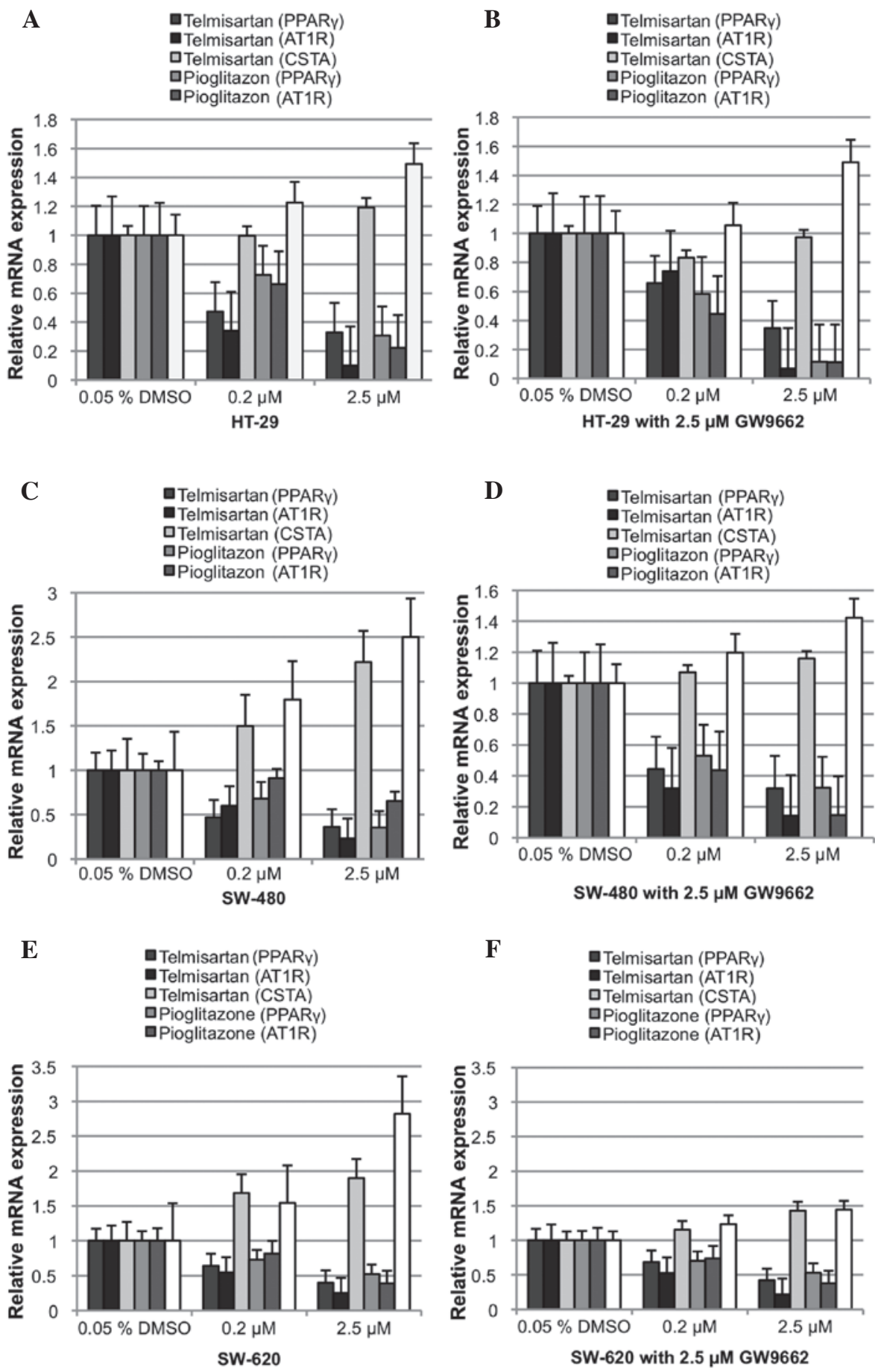

Figure 4. Relative mRNA expression of PPAR $\gamma$, the PPAR $\gamma$ target gene, CSTA and AT1R following 24 h of incubation with DMSO, pioglitazone and telmisartan. (A) HT-29 without and (B) with the PPAR $\gamma$ antagonist, GW9662. (C) SW-480 without and (D) with the PPAR $\gamma$ antagonist, GW9662. (E) SW-620 without and $(\mathrm{F})$ with the PPAR $\gamma$ antagonist, GW9662. PPAR $\gamma$, peroxizome proliferator-activated receptor $\gamma$; DMSO, dimethyl sulfoxide; CSTA, cystatin A; AT1R, angitensin I receptor.

pioglitazone or telmisartan only significantly downregulated relative PPAR $\gamma$ mRNA expression in all three colon cancer cell lines, while upregulating CSTA in an evidently dose-dependent manner. However, the additional blockage with $2.5 \mu \mathrm{M}$ GW9662 resulted in a significant downregulation in relative PPAR $\gamma$ mRNA expression.

In conclusion, the present study showed that telmisartan reduced cell viability and inhibited cell proliferation in selected colon cancer cell lines in a dose-dependent manner. Furthermore, telmisartan showed a greater effect than pioglitazone in the SW-480 and SW-620 cells, particularly in the presence of the PPAR $\gamma$ blocker, GW9662. The apoptotic effect of telmisartan was close to the full PPAR $\gamma$ agonist, pioglitazone, in all cell lines and was not inhibited by GW9662. PPAR $\gamma$ and CSTA mRNA expression appeared to be affected by the presence of GW9662. Therefore, the observed reduction in cell viability, the inhibition of cell proliferation and the induction of apoptosis by telmisartan cannot be completely explained by ligand-dependent $\operatorname{PPAR} \gamma_{1}$ activation. 
Telmisartan may be an alternative drug for patients presenting with arterial hypertension and colon cancer in their medical history. Understanding its mechanism of action may lead to similar pleiotropic drugs with increased potency.

\section{Acknowledgements}

The authors would like to thank Mr. Marco Arndt and Mrs. Sonja Dullat for providing excellent technical assistance.

\section{References}

1. Schupp M, Janke J, Clasen R, Unger T and Kintscher U: Angiotensin type 1 receptor blockers induce peroxisome proliferator-activated receptor-gamma activity. Circulation 109 2054-2057, 2004.

2. Mangelsdorf DJ, Thummel C, Beato M, et al: The nuclear receptor superfamily: the second decade. Cell 83: 835-839, 1995

3. Fajas L, Fruchart JC and Auwerx J: PPARgamma3 mRNA: a distinct PPARgamma mRNA subtype transcribed from an independent promoter. FEBS Lett 438: 55-60, 1998.

4. Matsuyama M, Funao K, Kuratsukuri K, et al: Telmisartan inhibits human urological cancer cell growth through early apoptosis. Exp Ther Med 1: 301-306, 2010.
5. Fajas L, Auboeuf D, Raspé E, et al: The organization, promoter analysis, and expression of the human PPARgamma gene. J Biol Chem 272: 18779-18789, 1997.

6. Bull AW: The role of peroxisome proliferator-activated receptor gamma in colon cancer and inflammatory bowel disease. Arch Pathol Lab Med 127: 1121-1123, 2003.

7. Sarraf P, Mueller E, Jones D, et al: Differentiation and reversal of malignant changes in colon cancer through PPARgamma. Nat Med 4: 1046-1052, 1998.

8. Bertz J, Dahm S, Haberland J, Kraywinkel K, Kurth B-M and Wolf U: Spread of Cancer in Germany. Development in the prevalence between 1990 and 2010. Robert Koch Institute, Berlin, 2010 (In German)

9. Semple TU, Quinn LA, Woods LK and Moore GE: Tumor and lymphoid cell lines from a patient with carcinoma of the colon for a cytotoxicity model. Cancer Res 38: 1345-1355, 1978.

10. Kato M, Kusumi T, Tsuchida S, Tanaka M, Sasaki M and Kudo H: Induction of differentiation and peroxisome proliferator-activated receptor gamma expression in colon cancer cell lines by troglitazone. J Cancer Res Clin Oncol 130: 73-79, 2004.

11. Stangier J, Su CA and Roth W: Pharmacokinetics of orally and intravenously administered telmisartan in healthy young and elderly volunteers and in hypertensive patients. J Int Med Res 28: 149-167, 2000. 